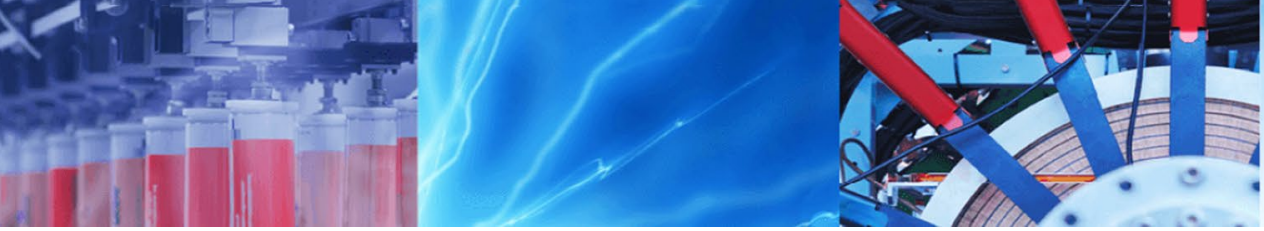

Research Article

\title{
A parametric study of the heat exchanger copper coils used in an indirect evaporative cooling system
}

\author{
Esmaeel Fatahian $^{1}$ (D) $\cdot$ Hesamoddin Salarian $^{1} \cdot$ Hossein Fatahian $^{1}$
}

Received: 4 November 2019 / Accepted: 16 December 2019 / Published online: 19 December 2019

(c) Springer Nature Switzerland AG 2019

\begin{abstract}
Due to the lower energy consumption in the evaporative cooling, it is the subject of numerous studies. Evaporative cooling considers a green cooling system which does not require any chemical reaction and does not depend on the hazardous material. The present study mainly focused on parametric analysis of an indirect evaporative cooling system using the computational fluid dynamics method. The numerical simulation of an indirect evaporative cooling system was carried out using ANSYS Fluent 18.2. The effects of the water inlet velocity, air inlet velocity, coil diameters $\left(d_{c}\right)$ and the number of the heat exchanger copper coils were numerically investigated. The flow was considered as threedimensional, turbulent, and incompressible. The results indicated that the increment of the coil diameter and water inlet velocity had a positive effect on the performance of the indirect evaporative cooling system. The maximum water outlet temperature was obtained at $285.05 \mathrm{~K}$ for the water inlet velocity of $0.5 \mathrm{~m} / \mathrm{s}$. Moreover, the saturation efficiency is decreased by increasing air inlet velocity. On the other hand, saturation efficiency was increased at all air inlet velocities by increasing the coil diameter.
\end{abstract}

Keywords Indirect evaporative cooling system · Heat exchanger · Computational fluid dynamics · Saturation efficiency

\section{Introduction}

The evaporative cooling system needs less input energy than mechanical vapor compression systems [1]. It has been taking place over the air-cooling system because the cooling process depends on the evaporation of water which is not harmful to the environment as well as requires less energy. The mechanical cooling system requires a higher cost for installation and higher energy where HVAC converts $100 \%$ outside air into the cool air. Evaporative cooling units can be used in a residential area, business buildings, and data center cooling. Evaporative cooling unit has two distinguished systems; Direct Evaporative Cooling unit (DEC) and indirect evaporative cooling system (IEC) [1-3]. An indirect evaporative cooler (IEC) is an energy-efficient cooling device which has been widely used to cool the air or other fluids [4-7]. Indirect evaporative cooling systems are air to air heat exchangers where the primary air is cooled by the secondary air. The secondary air is either cooled by Direct Evaporative Cooling before entering the air to air heat exchanger or it is cooled in the air to the air heat exchanger by wetting the secondary air stream side $[8,9]$. The indirect evaporative cooling unit is not efficient as Direct Evaporative Cooling so, in summer-time evaporative cooler has been placed in series for higher efficiency. Indirect evaporative cooling overcomes the disadvantages of a Direct Evaporative cooling unit of adding humidity in the air. Currently, many researchers are working on indirect evaporative cooling systems [10-13], dealing with new thermodynamic cycles, heat exchanger materials and geometries, humidification

Esmaeel Fatahian, esmaeelfatahian@gmail.com | 1 Department of Mechanical Engineering, Nour Branch, Islamic Azad University, Nour, Iran. 
systems and with the evaluation of energy savings compared to conventional devices.

Boxem et al. [14] introduced a model for an indirect evaporative cooler: a compact counter flow heat exchanger with louver fins on both sides. They demonstrated that their calculations overestimated the cooler performance by $20 \%$ for inlet air temperatures below $24^{\circ} \mathrm{C}$ and by $10 \%$ for higher inlet temperatures. ShariatyNiassar and Gilani [15] studied the effects of air stream direction in the channels of the indirect evaporative cooler (IEC). They found that a higher performance was achieved by using the indirect evaporative cooler with counter-current configuration. You et al. [16] presented a method of indirect evaporative cooling heat exchanger using the CFD method. They investigated the influence such as inlet air temperature, relative humidity, mass flow rate, and exchanger channel height. They concluded that lower inlet temperature and relative humidity could obtain lower outlet temperature and moisture content. Wan et al. [17] developed a new approach to investigate the coupled heat and mass transfer characteristics in an indirect evaporative cooling with counter-flow configurations. In their study, the effects of different parameters on the average Nusselt and Sherwood numbers were examined in detail. Pakari and Ghani [8] numerically and experimentally investigated the performance of a counterflow dew point evaporative cooling system. They found that the predicted outlet temperature of the cooling system by $1 \mathrm{D}$ and $3 \mathrm{D}$ models were in good agreement with the experimental results. De Antonellis et al. [18] examined an indirect evaporative cooler, based on a cross-flow heat exchanger. In their study, a new indirect evaporative cooling system model was developed, including the effects of secondary air humidification and surface wettability factor, as a function of working conditions. Wan et al. [19] used a CFD model to consider counter flow dew point evaporative coolers. The model indicated a maximum discrepancy of $6 \%$ against experimental data. The two-dimensions analyzed in the model were the length and width of the cooling system's channels. Li et al. [20] presented a comparative study of a counter-cross flow plate heat recovery exchanger, which operates as an indirect evaporative air cooler. Their results indicated that the outlet air temperature of the exchanger set vertically was lower than that of exchanger set horizontally.

Despite the above-mentioned researches, any numerical study has not been yet done to analyze the copper coil diameter variation. The present study is mainly focused on investigating the effect of coil diameter on the performance of an indirect evaporative cooling (IEC) system as well as obtaining favorable water and air inlet velocities simultaneously. On the other hand, cooling coil efficiency not only depends on water and air temperature but also depends on coil diameter, number of coils, water inlet velocity, and air inlet velocity. For this purpose, three different coil diameters $\left(d_{c}\right)$ of $0.0127,0.01905$ and $0.0254 \mathrm{~m}$ were used. In addition, wide ranges of air inlet velocities between $0.1 \mathrm{~m} / \mathrm{s}$ to $0.6 \mathrm{~m} / \mathrm{s}$ and water inlet velocities between $0.1 \mathrm{~m} / \mathrm{s}$ to $0.5 \mathrm{~m} / \mathrm{s}$ were considered at each different coil diameters to achieve the favorable parameters. The outcome of this work could be helpful to find out the best configuration of an indirect evaporative cooling system through parametric study in CFD simulation for reallife implementation.

\section{Model description}

In the present study, 8-row chilled water cooling coils with a length of $0.5 \mathrm{~m}$ and a diameter of $0.0127 \mathrm{~m}$ were used which the distance between the coils was $0.05 \mathrm{~m}$. The entire coils were placed in a rectangular cube of $2 \mathrm{~m}$ in length, 0.75 in width and $1 \mathrm{~m}$ in height for applying the boundary conditions. The geometry of an indirect evaporative cooling system is shown in Fig. 1 [21] and Fig. 2 illustrates the side view of its geometry.

\section{Governing equations}

In the present study, the flow was considered as threedimensional, turbulent, and incompressible. The CFD code ANSYS Fluent solves continuity, momentum and energy equations along with species transport. Equations (1) and (2) represent the continuity and momentum equations used in this case, respectively [22]. Here acceleration due to droplet particle and viscous forces are considered [22].

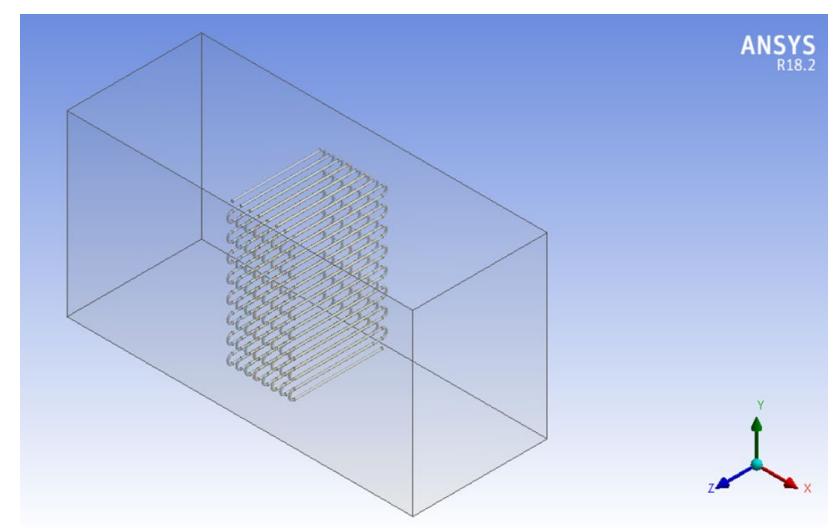

Fig. 1 The geometry of an Indirect Evaporative Cooling (IEC) system [21] 


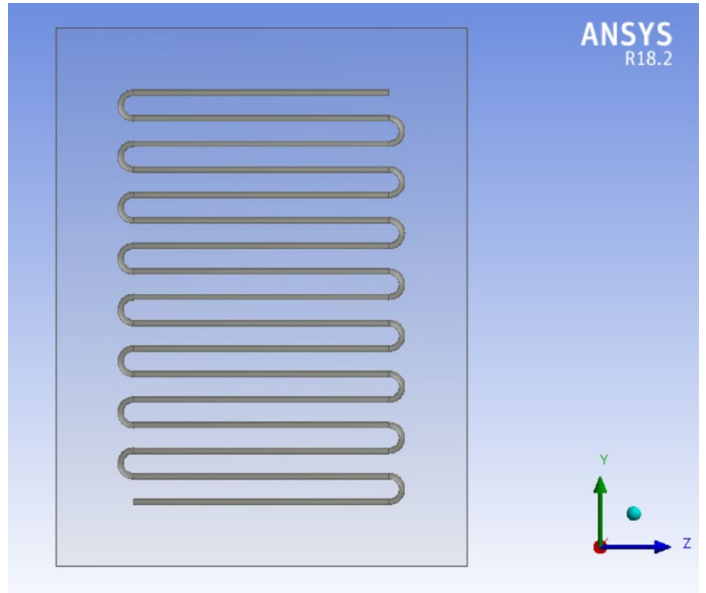

Fig. 2 The side view of the geometry of an Indirect Evaporative Cooling (IEC) system [21]

$\frac{\partial \rho}{\partial \mathrm{t}}+\nabla \cdot(\rho \vec{v})=S_{D P M}+S_{\text {Other }}$

where $\rho=$ density of the fluid phase, $\vec{v}=$ velocity in vector form, $S_{D P M}=$ discrete phase model source, $S_{\text {other }}=$ additional mass source

$\frac{\partial \rho \vec{v}}{\partial \mathrm{t}}+\nabla \cdot(\rho \vec{v} \vec{v})=-\nabla \mathrm{p}+\nabla \tau+\rho \mathrm{g}+F_{D P M}$

where $\mathrm{P}=$ static pressure, $\mathrm{\tau}=$ stress tensor, $\mathrm{g}=$ gravitational acceleration, $F_{D P M}=$ DPM force acceleration.

Water vapor in the air is modeled using species transport in ANSYS Fluent 18.2. Species transport equation uses convection-diffusion phenomena to transport water vapor in the air which is presented in Eq. (3).

$\frac{\partial \rho Y_{i}}{\partial \mathrm{t}}+\nabla \cdot\left(\rho \vec{\imath} Y_{i}\right)=-\nabla \cdot \vec{J}_{i}+\vec{S}_{i}$

where $Y_{i}=$ local mass fraction of each species, $J i=$ diffusive flux, $S_{i}=$ creation of species by DPM.

Heat transfer is governed by the energy equation which is presented in Eq. (4) [22].

$\frac{\partial \rho \mathrm{E}}{\partial \mathrm{t}}+\nabla \cdot(\vec{v}(\rho \mathrm{E}+\mathrm{p}))=\nabla \cdot\left(\mathrm{k}_{\text {eff }} \nabla \mathrm{T}-\sum_{j} h_{j} \vec{\jmath}_{i}+\overline{\bar{\tau}}_{\text {eff }} \cdot \vec{v}\right)$

where $\mathrm{E}=$ enthalpy, $K_{\text {eff }}=$ effective thermal conductivity, $J_{i}=$ diffusive flux due to species.

Using the above governing equations for the flow simulation with enabling species transport equation and $\mathrm{k}-\varepsilon$ turbulence model has been carried out. The equations in the $\mathrm{k}-\varepsilon$ turbulence model are as follows:

Turbulent kinetic energy (k) [23]:

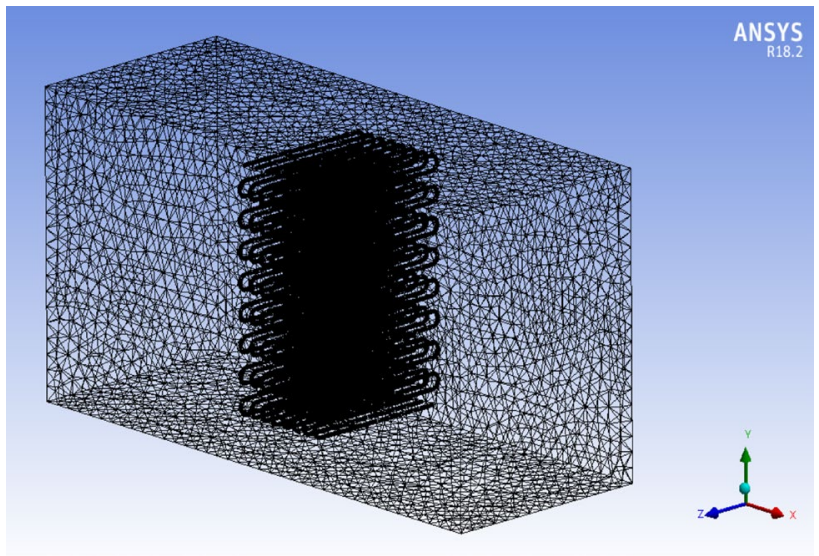

Fig. 3 The entire view of the grid

$\rho \frac{\partial \mathrm{k}}{\partial \mathrm{t}}+\rho \overline{\mathrm{u}_{\mathrm{j}}} \frac{\partial \mathrm{k}}{\partial \mathrm{x}_{\mathrm{j}}}=\tau_{\mathrm{ij}} \frac{\partial \overline{\mathrm{u}_{\mathrm{j}}}}{\partial \mathrm{x}_{\mathrm{j}}}-\rho \varepsilon+\frac{\partial}{\partial \mathrm{x}_{\mathrm{j}}}\left[\left(\mu+\mu_{\mathrm{t}} / \sigma_{\mathrm{k}}\right) \frac{\partial \mathrm{k}}{\partial \mathrm{x}_{\mathrm{j}}}\right]$

The rate of turbulence energy dissipation $(\varepsilon)$ [22]:

$\rho \frac{\partial \varepsilon}{\partial \mathrm{t}}+\rho \overline{\mathrm{u}}_{\mathrm{j}} \frac{\partial \varepsilon}{\partial \mathrm{x}_{\mathrm{j}}}=\mathrm{C}_{\varepsilon 1} \frac{\varepsilon}{\mathrm{k}} \tau_{\mathrm{ij}} \frac{\partial \overline{\mathrm{u}_{\mathrm{i}}}}{\partial \mathrm{x}_{\mathrm{j}}}-\mathrm{C}_{\varepsilon 2} \rho \frac{\varepsilon^{2}}{\mathrm{k}}+\frac{\partial}{\partial \mathrm{x}_{\mathrm{i}}}\left[\left(\mu+\mu_{\mathrm{t}} / \sigma_{\varepsilon}\right) \frac{\partial \varepsilon}{\partial \mathrm{x}_{\mathrm{j}}}\right]$.

\section{Grid generation and numerical method}

In the present study, tetrahedral meshes have been used for the inlet and outlet regions of the computational area. Moreover, fine meshes were applied for the areas which are more sensitive in order to have high accuracy in computations. Figures 3 and 4 demonstrate the entire and the side view of the grid, respectively. For the inlet side, the boundary condition was set to inlet velocity and for the outlet side, the boundary condition was set to outlet pressure. Furthermore, the no-slip boundary condition was set for the coils. The water with a density of $998.2 \mathrm{~kg} / \mathrm{m}^{3}$ and a viscosity of $0.001003 \mathrm{~kg} / \mathrm{m}$ s and also the air with a density of $1.225 \mathrm{~kg} / \mathrm{m}^{3}$ and a viscosity of $1.7894 \times 10^{-5} \mathrm{~kg} / \mathrm{m}$ s were considered as the working fluids. The water inlet temperature was $275 \mathrm{~K}$ and the hot air inlet temperature was $300 \mathrm{~K}$ with a relative humidity of $34.9 \%$. For the inlet section of the coils, the boundary condition was set to inlet velocity and for the outlet section of the coils, the boundary condition was set to outlet pressure (Fig. 5). The Reynolds number was considered from 6300 to 12,640 for different coil diameters at a water inlet velocity of $0.5 \mathrm{~m} / \mathrm{s}$ so the flow was assumed to be turbulent. 


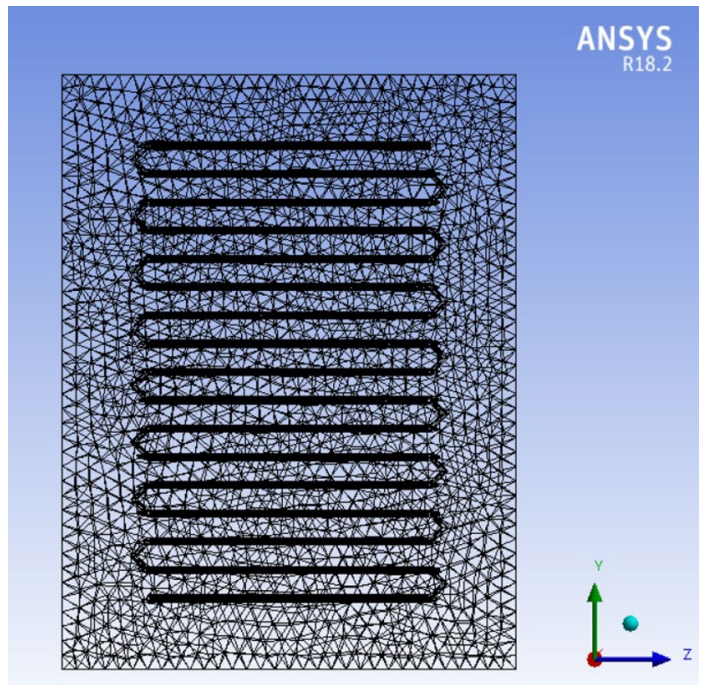

Fig. 4 The side view of the grid

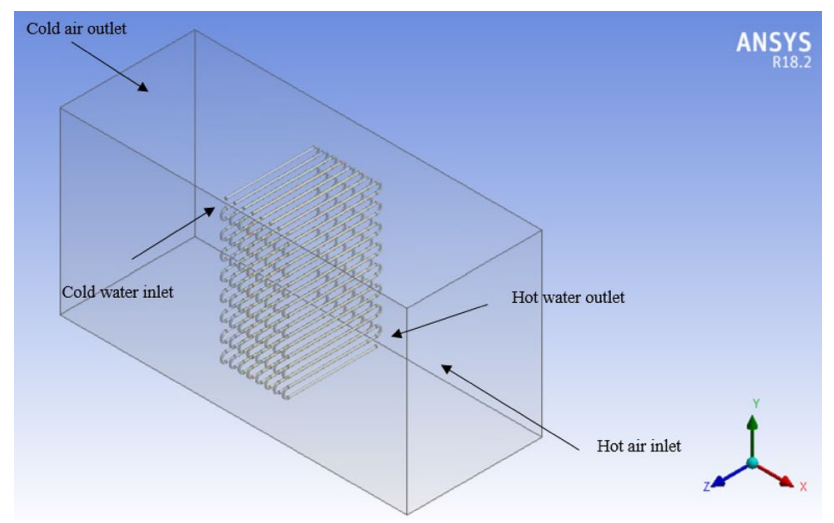

Fig. 5 Boundary conditions

The numerical analysis was carried out using ANSYS Fluent 18.2 based on the CFD codes which are used to describe the complex behaviors of the heat and mass transfer [24-26] and also are implemented in various problems [27-29]. The upwind second-order method was applied for the discretization of continuity, momentum, and energy equations. In addition, The SIMPLE algorithm was used for pressure-velocity coupling and pressure interpolation was second-order [30]. The convergence criteria were considered to be less than $10^{-6}$ for all equations. Due to the high Reynolds number flow inside the coils, the fluid governing equations consist of Reynolds-Averaged Navier-Stokes (RANS) equations. Modeling of the turbulence behavior inside the coil

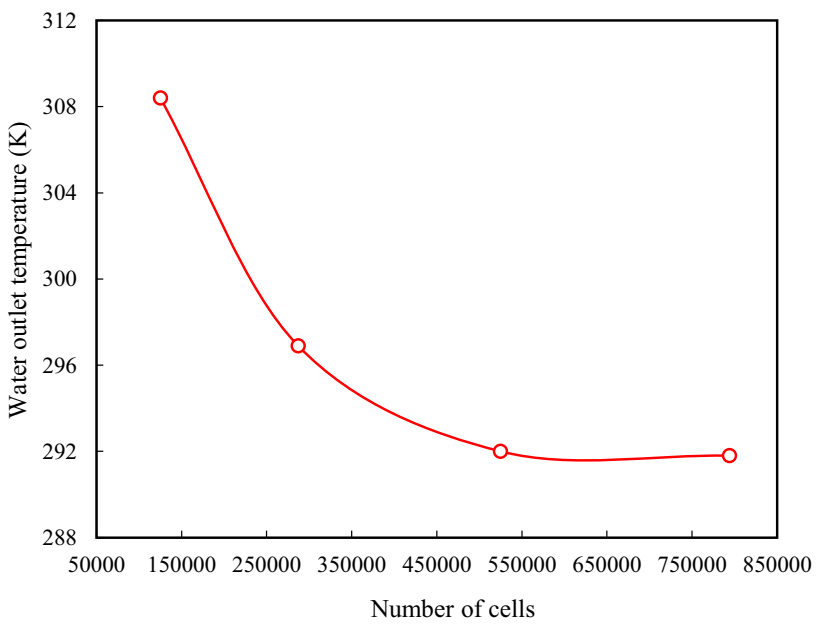

Fig. 6 The detail of grid independence

Table 1 Comparison of temperature variations of the CFD results with the experimental results [21]

\begin{tabular}{lll}
\hline Validation & $\begin{array}{l}\text { Air outlet tem- } \\
\text { perature (K) }\end{array}$ & $\begin{array}{l}\text { Water outlet } \\
\text { temperature } \\
(\mathrm{K})\end{array}$ \\
\hline Present study & 292 & 284.9 \\
Experimental results [21] & 289.55 & 287.85 \\
Error\% & $0.85 \%$ & $1 \%$ \\
\hline
\end{tabular}

was performed using a standard $\mathrm{k}-\varepsilon$ turbulence model according to the recommendations of previous studies for similar flows [31-33].

\section{Grid independence study and validation}

A grid independence study was conducted to verify the adequacy of the final grid with cell numbers of 125,000 , $287,000,525,000$ and 794,000 to calculate the water outlet temperature. Finally, there was a negligible difference between the results of the finest grid and the grid with 525,000 cells. Thus, in order to select a favorable grid size to save computation time and gain better accuracy, the grid with 525,000 cells was used to obtain the results. Figure 6 indicates the detail of grid independence. Moreover, in order to validate the computational results, the values of water outlet temperature and air outlet temperature compared with the experimental results of Zhou et al. [21] at a Reynolds number of 6320 (Table 1). As it can be seen, the results obtained from the numerical simulation had a good agreement with the available experimental data [21]. 


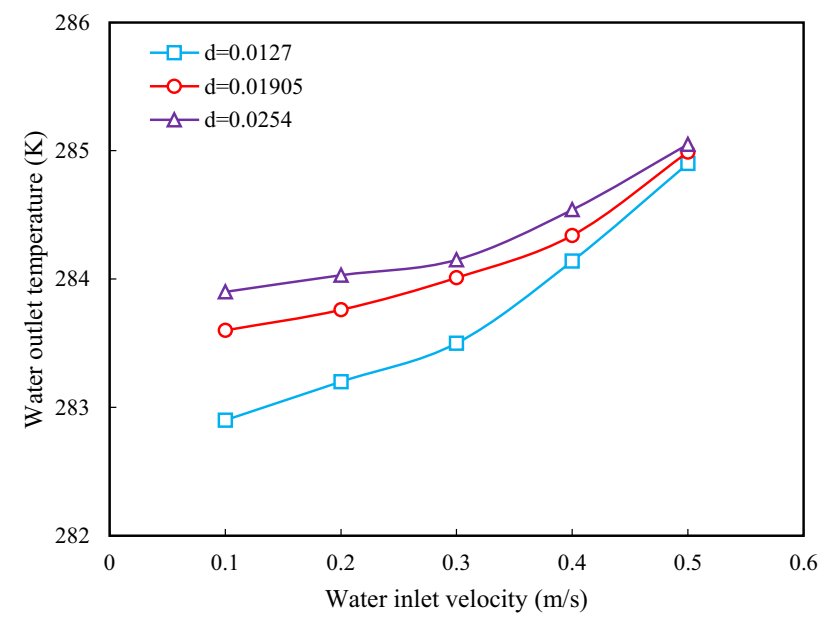

Fig. 7 Comparison of the changes in water outlet temperature in terms of the changes in water inlet velocity

\section{Results and discussion}

\subsection{The effect of coil diameter on the water outlet temperature}

Figure 7 shows the changes in the water outlet temperature in terms of the changes in the water inlet velocity between 0.1 and $0.5 \mathrm{~m} / \mathrm{s}$ for three different coil diameters. For this purpose, three different coil diameters of $0.0127,0.01905$ and $0.0254 \mathrm{~m}$ were used. The coil diameter of 0.0127 was selected as the base diameter which was consistent with the coil diameter of available experimental data [21] and the other diameters were 0.01905 $\left(1.5 d_{c}\right)$ and $0.0254\left(2 d_{c}\right)$.

It is obvious that the water outlet temperature had increased with the increment of water inlet velocity for all the coil diameters. The water inlet temperature was $275 \mathrm{~K}$ and the hot air temperature was $300 \mathrm{~K}$. After passing through 8 rows of copper coils, the water temperature gradually increased by colliding the hot airflow with the coils, and the hot water was exited at the outlet side of the coil. Also, the entered hot air due to the collision with the coils lost its heat and the cool air was exited from the outlet side. It is clear that the increment of coil diameter affects the performance of the indirect evaporative cooling (IEC) system so that the water outlet temperature had increased by increasing coil diameters. This positive effect is more evident in low water inlet velocity especially at a water inlet velocity of $0.1 \mathrm{~m} / \mathrm{s}$. On the other hand, the outlet water temperature had increased by increasing the water inlet velocity. The maximum water outlet temperature was obtained $285.05 \mathrm{~K}$ at a water inlet velocity of $0.5 \mathrm{~m} / \mathrm{s}$ for a coil diameter of
$0.0254 \mathrm{~m}$, which increased about $3.65 \%$ compared to the water inlet temperature of $275 \mathrm{~K}$.

\subsection{The effect of coil diameter on the air outlet temperature}

Figure 8 demonstrates the changes in the air outlet temperature in terms of the changes in the air inlet velocity between 0.1 and $0.6 \mathrm{~m} / \mathrm{s}$ for three different coil diameters. As it can be seen, the air outlet temperature had increased with the increment of air inlet velocity for all coil diameters. In contrary to the effect of water inlet velocity, lower values of air inlet velocity had more effect on the performance of the indirect evaporative cooling system. Moreover, a larger coil diameter had more effect on decreasing the air outlet temperature so the best value was obtained at the inlet air velocity of $0.1 \mathrm{~m} / \mathrm{s}$ and a coil diameter of $0.0254 \mathrm{~m}$. At the inlet air velocity of $0.1 \mathrm{~m} / \mathrm{s}$, the maximum reduction of the air outlet temperature was obtained about $5.3 \%, 5.1 \%$ and $4.5 \%$ at coil diameters of $0.0254,0.01905$ and $0.0127 \mathrm{~m}$, respectively.

\subsection{Saturation efficiency}

Figure 9 depicts the saturation efficiency in terms of the changes in the air inlet velocity between 0.1 and $0.6 \mathrm{~m} / \mathrm{s}$ for three different coil diameters. Saturation efficiency equation is obtained as follows:

$\varepsilon_{e}=\frac{t_{1}-t_{2}}{t_{1}-t^{\prime}} 100 \%$

where $\varepsilon_{e}=$ saturation efficiency, $\%, \mathrm{t}_{1}=$ dry-bulb temperature of entering air, $K, t_{2}=d r y$-bulb temperature of exiting air, $\mathrm{K}, t^{\prime}=$ wet bulb temperature of entering the air, $\mathrm{K}$.

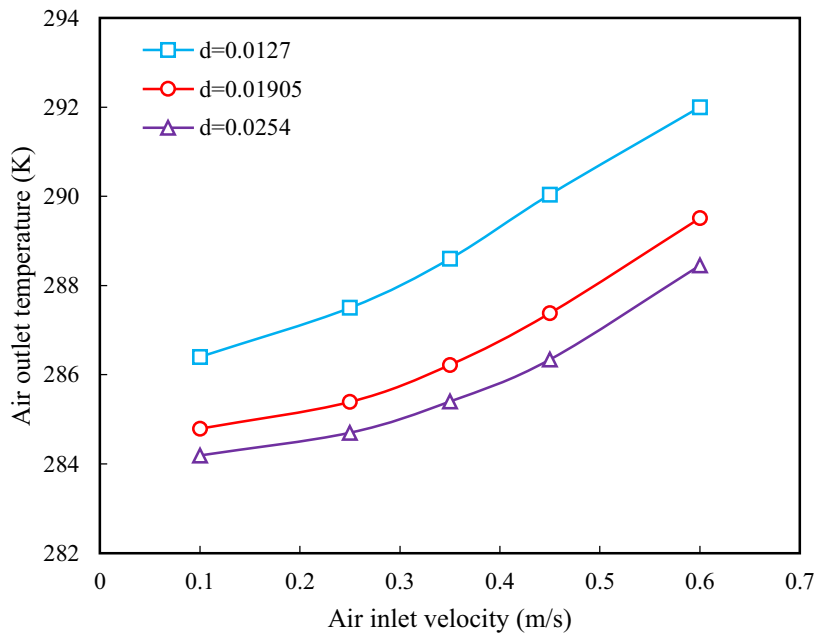

Fig. 8 Comparison of the changes in air outlet temperature in terms of the changes in air inlet velocity 


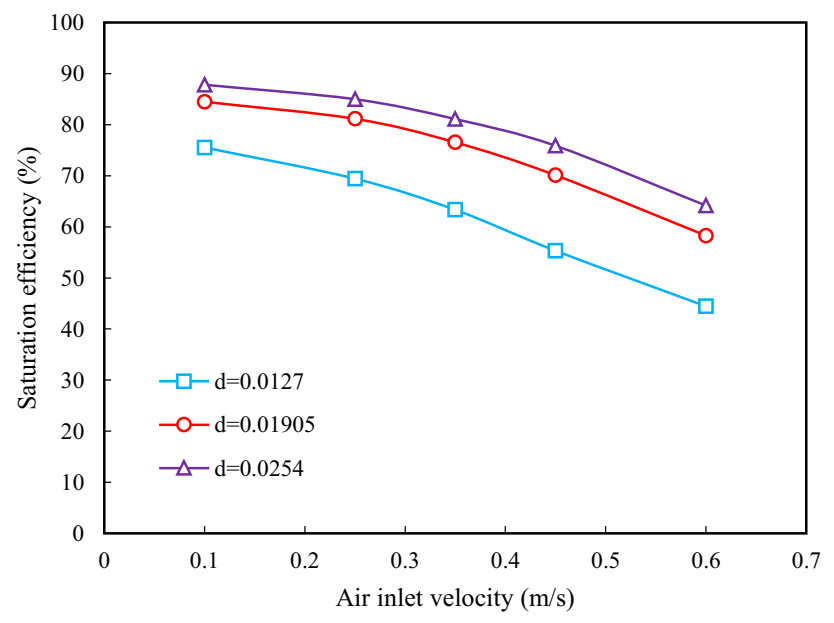

Fig. 9 Comparison of saturation efficiency in terms of the changes in air inlet velocity

A user-defined function (UDF) for computing the saturation efficiency was developed and added to FLUENT to be incorporated into the conservation equations. First, the values of density, pressure, temperature, and mass fraction were read by existing macros in FLUENT. Then, the specific gas constant of water vapor and dry air were defined as constants from which the gas constant for the mixture was calculated based on the components' mass fractions. A fixed mass fraction of $\mathrm{H}_{2} \mathrm{O}$ was calculated based on the air temperature and relative humidity, imposed at the inlet for the species transport equation. The dry and wet bulb temperatures of entering air were given as flow conditions. The dry-bulb temperature of exiting air was calculated after solving governing equations for the flow simulation with enabling species transport equation.

It is obvious that the saturation efficiency was decreased with the increment of air inlet velocity. On the other hand, saturation efficiency was increased at all air inlet velocities by increasing coil diameter. The maximum saturation efficiency was obtained $87.83 \%$ at a coil diameter of $0.0254 \mathrm{~m}$ and air inlet velocity of $0.1 \mathrm{~m} / \mathrm{s}$ which was about $4 \%$ and $14 \%$ higher than coil diameters of $0.01905 \mathrm{~m}$ and $0.0127 \mathrm{~m}$, respectively.

\subsection{The effect of coil diameter on pressure drop}

The pressure drop for all three coil diameters was calculated at an air inlet velocity of $0.5 \mathrm{~m} / \mathrm{s}$ and water inlet velocity of $0.6 \mathrm{~m} / \mathrm{s}$ which is presented in Table 2 . As it can be seen, the pressure drop had decreased by increasing coil diameter so that the pressure drop was reduced about $56 \%$ in a coil diameter of $0.0254 \mathrm{~m}$ compared to the coil diameter of $0.0127 \mathrm{~m}$.

SN Applied Sciences
Table 2 Comparison of pressure drop $(\mathrm{Pa})$ between three different coil diameters

\begin{tabular}{lll}
\hline Case & Pressure drop $(\mathrm{Pa})$ & Coil diameter $(\mathrm{m})$ \\
\hline 1 & 14.62 & 0.0127 \\
2 & 9.77 & 0.01905 \\
3 & 6.43 & 0.0254 \\
\hline
\end{tabular}

\subsection{The changes in Nusselt number against Reynolds number}

Figure 10 shows the changes in the Nusselt number against Reynolds number for three different coil diameters. From this figure, the Nusselt number had increased considerably by increasing the Reynolds number for all coil diameters. Furthermore, increasing coil diameter had a significant effect on increasing Nusselt number. The maximum value of the Nusselt number was obtained for a coil diameter of $0.0254 \mathrm{~m}$.

\subsection{The effect of the number of coils}

Figures 11 and 12 illustrate the effect of the number of coils on changes of water and air outlet temperatures for a coil diameter of $0.0127 \mathrm{~m}$. For this purpose, three different rows of copper coils ( 4,6 and 8 rows) were considered. It is concluded that the number of coils has a significant effect on the performance of an indirect evaporative cooling (IEC) system. As the number of coils increased, the collision of hot airflow with the coils had increased. This caused to enhance the heat transfer rate and consequently reduce the air outlet temperature. On the other hand, a higher number of coils led to increase in the water outlet temperature. The maximum water outlet temperature was obtained $284.9 \mathrm{~K}$ for 8 rows of copper coils at a water inlet velocity of $0.5 \mathrm{~m} / \mathrm{s}$ which increased about $1 \%$ and $0.42 \%$ compared to 4 rows and 6 rows copper coils, respectively. Furthermore, the maximum reduction of the air outlet temperature was obtained about $2.7 \%, 2.2 \%$ and $1.8 \%$ for 8 rows, 6 rows and 4 rows of copper coils at an air inlet velocity of $0.6 \mathrm{~m} / \mathrm{s}$, respectively.

\subsection{The temperature and velocity distributions}

The temperature distribution $(\mathrm{K})$ of the indirect evaporative cooling (IEC) system was investigated for three different coil diameters at an air inlet velocity of $0.6 \mathrm{~m} / \mathrm{s}$ and water inlet velocity of $0.5 \mathrm{~m} / \mathrm{s}$ which is illustrated in Figs. 13, 14, 15. As mentioned before, the passing hot airflow by colliding with the coils was exited from the outlet side with a reduction in temperature. Moreover, 

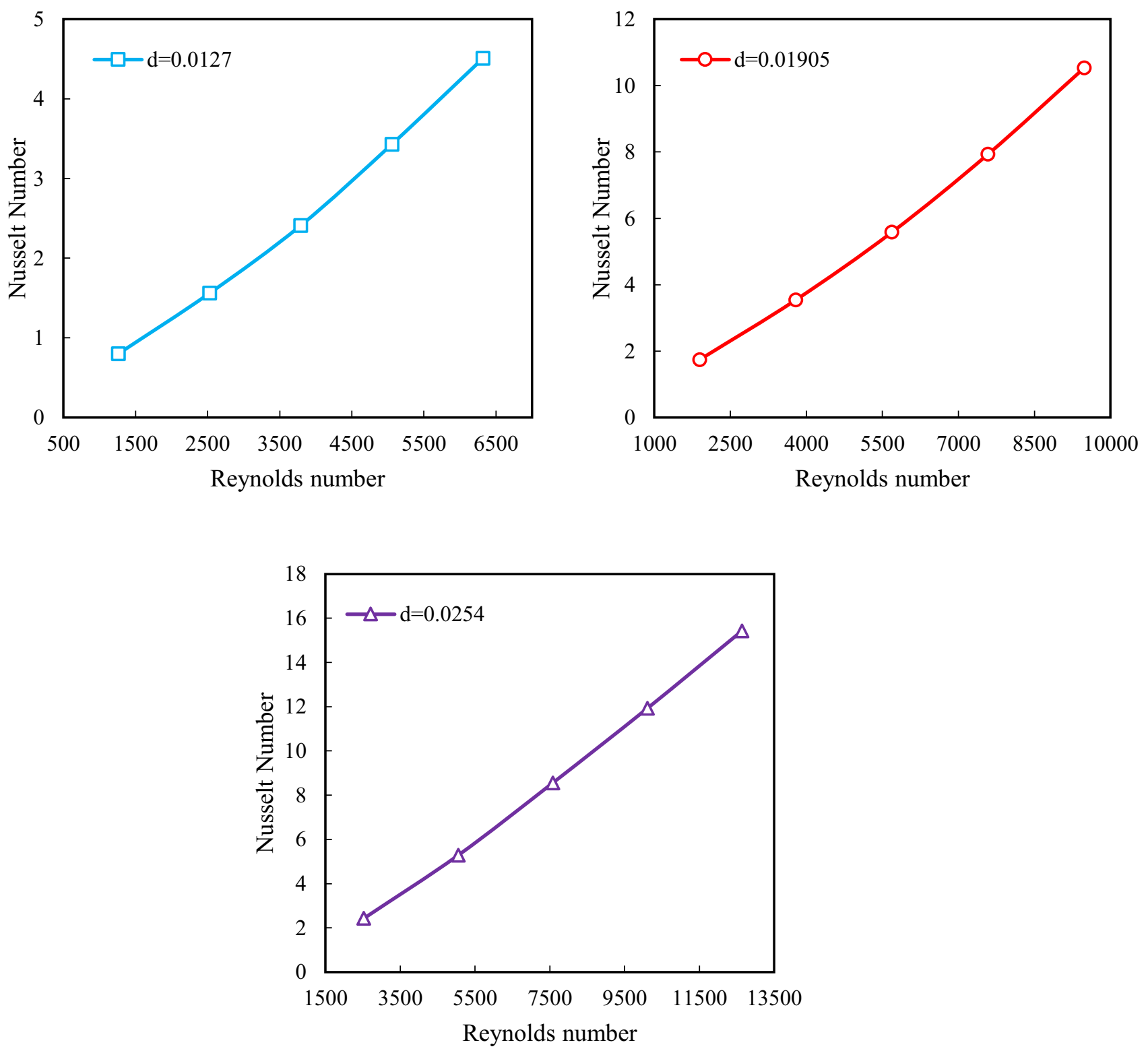

Fig. 10 Comparison of Nusselt number against Reynolds number for three different coil diameters

the water in the coils was heated and exited from the outlet side of the coils. Figures 16, 17, 18 demonstrate the velocity distribution $(\mathrm{m} / \mathrm{s})$ of the indirect evaporative cooling system which is considered for three different coil diameters at an air inlet velocity of $0.6 \mathrm{~m} / \mathrm{s}$ and water inlet velocity of $0.5 \mathrm{~m} / \mathrm{s}$. The velocity increases as it passes through the coil arrangement which increases convective heat transfer. Also, the velocity field indicates turbulence flow in the region before passing the coil arrangement which is the consequence of this fact that the pre-existing air is not evenly distributed between coils.

\section{Conclusions}

In the present study, a parametric analysis of an indirect evaporative cooling (IEC) system was carried out using the CFD method. The effects of the water inlet velocity, air inlet velocity, and coil diameters and the number of the heat exchanger copper coils were numerically analyzed. For this purpose, three different coil diameters of $0.0127,0.01905$ and $0.0254 \mathrm{~m}$ were used. The flow was considered as three-dimensional, turbulent, and incompressible. The SIMPLE algorithm was used for pressure-velocity coupling and also the $k-\varepsilon$ turbulence model was adapted to simulate the turbulence flow. For 


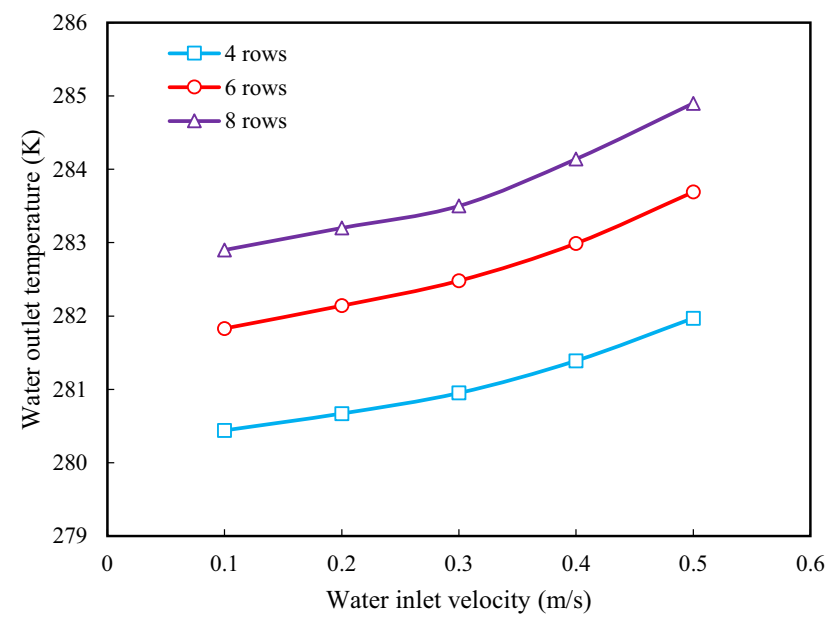

Fig. 11 Changes in water outlet temperature due to the number of coils with $d=0.0127 \mathrm{~m}$

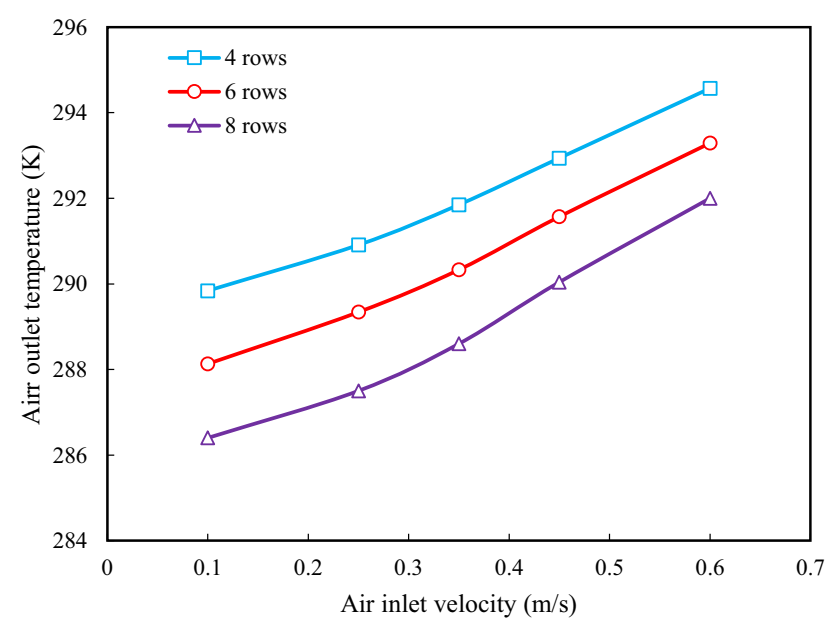

Fig. 12 Changes in air outlet temperature due to the number of coils with $d=0.0127 \mathrm{~m}$

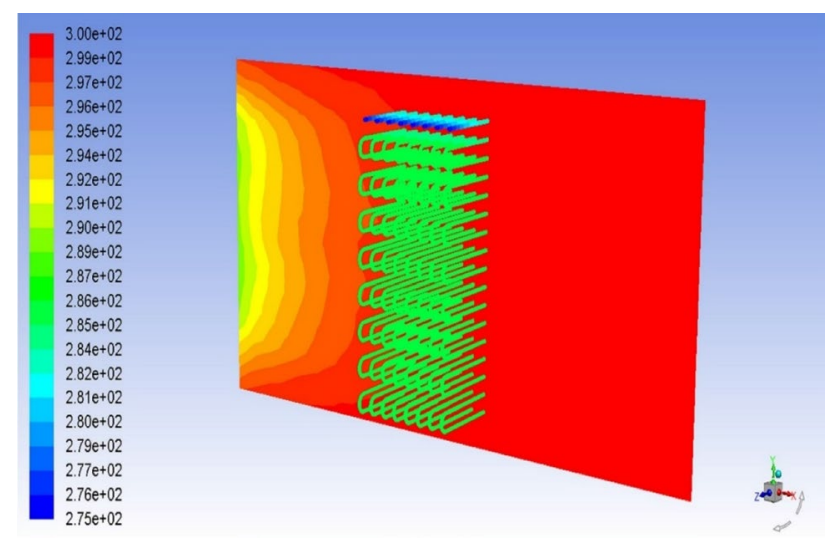

Fig. 13 Temperature distribution (K) for a coil diameter of $0.0127 \mathrm{~m}$

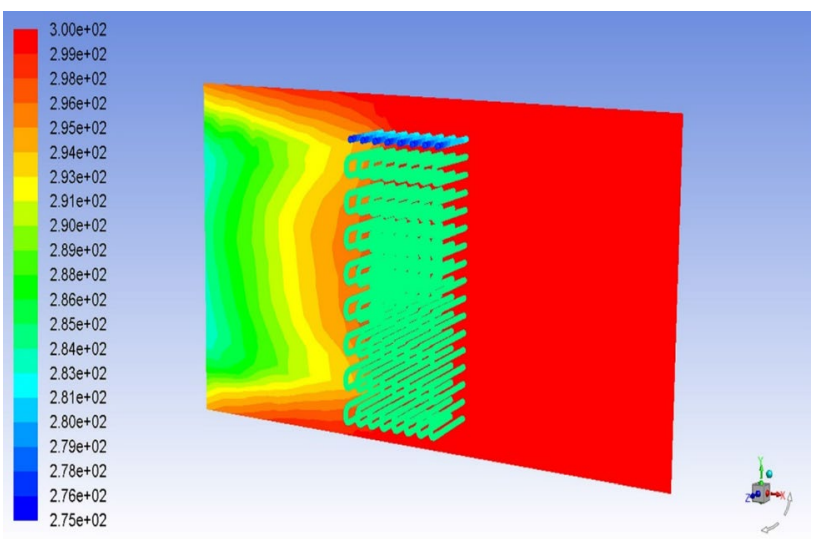

Fig. 14 Temperature distribution (K) for a coil diameter of $0.01905 \mathrm{~m}$

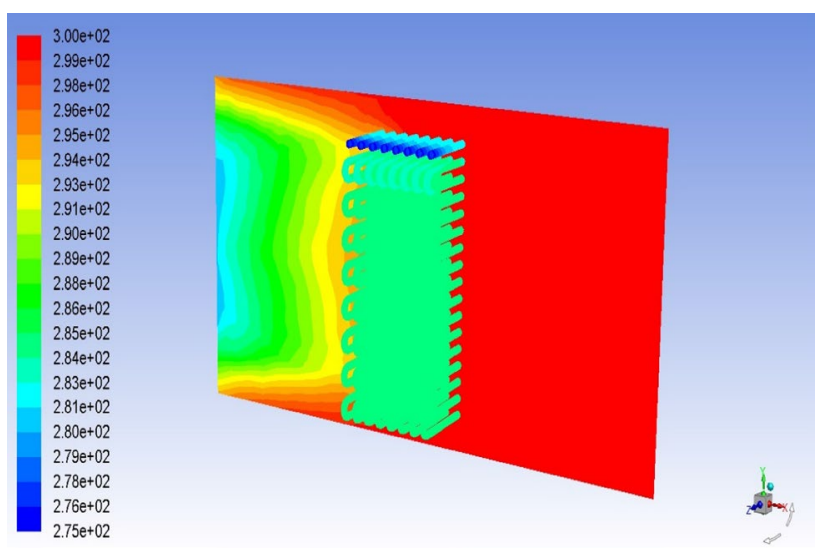

Fig. 15 Temperature distribution (K) for a coil diameter of $0.0254 \mathrm{~m}$

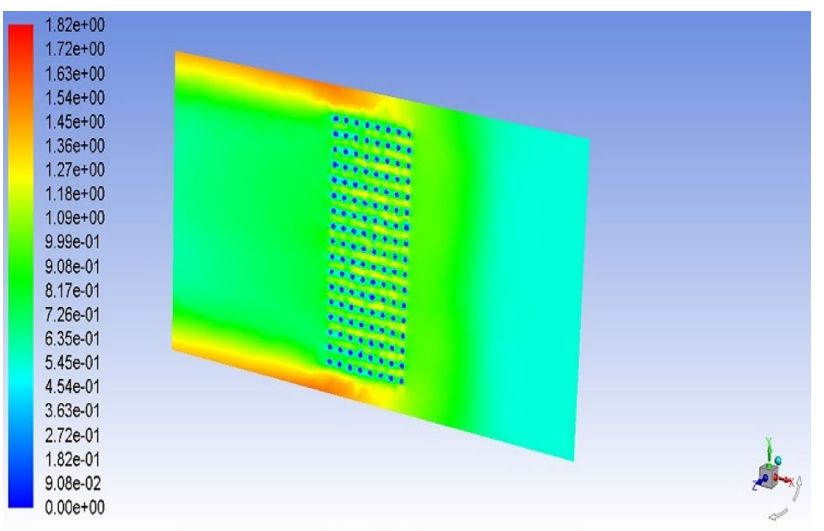

Fig. 16 Velocity distribution $(\mathrm{m} / \mathrm{s})$ for a coil diameter of $0.0127 \mathrm{~m}$

validation, the computational results compared with the available experimental results of Zhou et al. [21] and good agreement was achieved. Based on the results, it was concluded that a larger value of coil diameter and

\section{SN Applied Sciences}




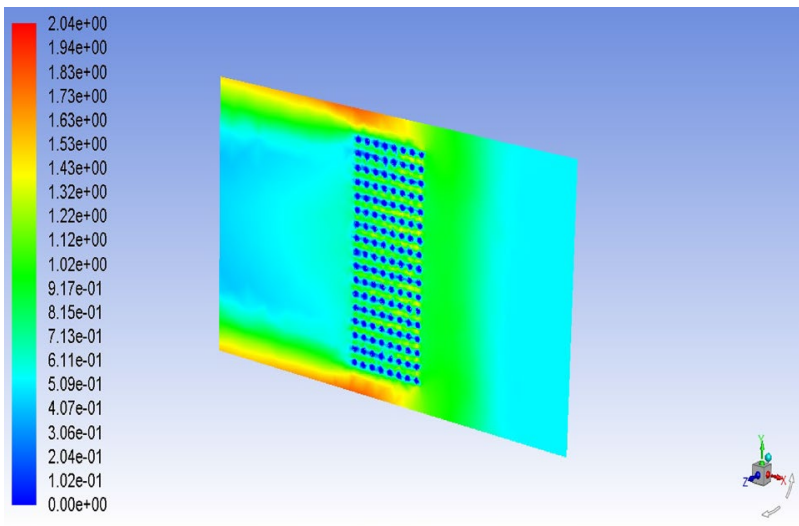

Fig. 17 Velocity distribution $(\mathrm{m} / \mathrm{s})$ for a coil diameter of $0.01905 \mathrm{~m}$

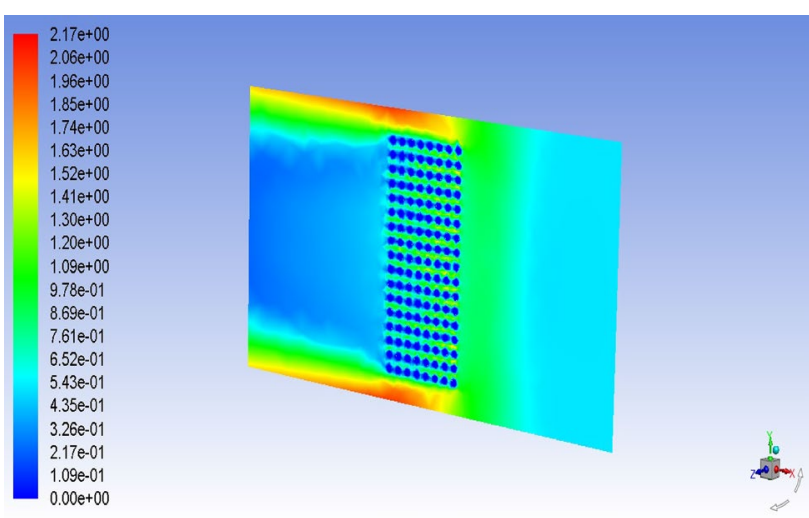

Fig. 18 Velocity distribution $(\mathrm{m} / \mathrm{s})$ for a coil diameter of $0.0254 \mathrm{~m}$

higher water inlet velocity improved the performance of the indirect evaporative cooling (IEC) system. The maximum saturation efficiency was obtained $87.83 \%$ at a coil diameter of $0.0254 \mathrm{~m}$ and air inlet velocity of $0.1 \mathrm{~m} / \mathrm{s}$ which was about $4 \%$ and $14 \%$ higher than coil diameters of $0.01905 \mathrm{~m}$ and $0.0127 \mathrm{~m}$, respectively. The maximum water outlet temperature was obtained $285.05 \mathrm{~K}$ at the water inlet velocity of $0.5 \mathrm{~m} / \mathrm{s}$ for a coil diameter of $0.0254 \mathrm{~m}$, which increased up to $3.65 \%$. On the other hand, lower values of air inlet velocity had more effect on the performance of the indirect evaporative cooling system. The maximum reduction of the air outlet temperature was obtained about $5.3 \%, 5.1 \%$ and $4.5 \%$ at an air inlet velocity of $0.1 \mathrm{~m} / \mathrm{s}$ and coil diameters of 0.0254 , 0.01905 and $0.0127 \mathrm{~m}$, respectively.

\section{Compliance with ethical standards}

Conflict of interest The authors declare that they have no conflict of interest.

\section{References}

1. Heidarinejad G, Moshari S (2015) Novel modeling of an indirect evaporative cooling system with cross-flow configuration. Energy Build 92:351-362

2. Al-Abbasi O, Al-Alawi Y (2019) Modeling of indirect evaporative cooling and its performance analysis in harsh environments. Heat Mass Transf 55:1-14

3. Duan Z, Zhan C, Zhang X, Mustafa M, Zhao X, Alimohammadisagvand $B$, Hasan A (2012) Indirect evaporative cooling: past, present, and future potentials. Renew Sustain Energy Rev 16(9):6823-6850

4. Bravo G, González E (2013) Thermal comfort in naturally ventilated spaces and under indirect evaporative passive cooling conditions in hot-humid climate. Energy Build 63:79-86

5. Lin J, Bui DT, Wang R, Chua KJ (2018) On the fundamental heat and mass transfer analysis of the counter-flow dew point evaporative cooler. Appl Energy 217:126-142

6. Cruz EG, Krüger E (2015) Evaluating the potential of an indirect evaporative passive cooling system for Brazilian dwellings. Build Environ 87:265-273

7. Rogdakis ED, Koronaki IP, Tertipis DN (2014) Experimental and computational evaluation of a Maisotsenko evaporative cooler at Greek climate. Energy Build 70:497-506

8. Pakari A, Ghani S (2019) "Comparison of 1D and 3D heat and mass transfer models of a counter flow dew point evaporative cooling system: numerical and experimental study. Int J Refrig 99:114-125

9. Heidarinejad G, Bozorgmehr M, Delfani S, Esmaeelian J (2009) Experimental investigation of two-stage indirect/direct evaporative cooling system in various climatic conditions. Build Environ 44:2073-2079

10. Sohani A, Sayyaadi H, Azimi M (2019) Employing static and dynamic optimization approaches on a desiccant-enhanced indirect evaporative cooling system. Energy Convers Manag 199:112017

11. Comino F, Milani S, De Antonellis S, Joppolo CM, de Adana MR (2018) Simplified performance correlation of an indirect evaporative cooling system: development and validation. Int J Refrig 88:307-317

12. Sohani A, Sayyaadi H, Zeraatpisheh M (2019) "Optimization strategy by a general approach to enhance improving potential of dew-point evaporative coolers. Energy Convers Manag 188:177-213

13. Pandelidis D, Cichoń A, Pacak A, Anisimov S, Drąg P (2018) Counter-flow indirect evaporative cooler for heat recovery in the temperate climate. Energy 165:877-894

14. Boxem G, Boink S, Zeiler W (2007) Performance model for the small-scale indirect evaporative cooler. In: Proceedings of clima wellbeing indoors, REHVA World Congress, Helsinki, Finland, pp. 10-14

15. Shariaty-Niassar M, Gilani N (2009) An investigation of indirect evaporative coolers, IEC with respect to thermal comfort criteria. Iran J Chem Eng 6(2):15-25

16. You Y, Jiang H, Lv J (2019) Analysis of influence of IEC heat exchanger based on CFD method. Energy Procedia 158:5759-5764

17. Wan Y, Ren C, Xing L (2017) An approach to the analysis of heat and mass transfer characteristics in indirect evaporative cooling with counterflow configurations. Int J Heat Mass Transf 108:1750-1763

18. De Antonellis S, Joppolo CM, Liberati P, Milani S, Romano F (2017) Modeling and experimental study of an indirect evaporative cooler. Energy Build 142:147-157 
19. Wan Y, Lin J, Chua KJ, Ren C (2018) Similarity analysis and comparative study on the performance of counter-flow dew point evaporative coolers with experimental validation. Energy Convers Manag 169:97-110

20. Li WY, Li YC, Zeng LY, Lu J (2018) Comparative study of vertical and horizontal indirect evaporative cooling heat recovery exchangers. Int J Heat Mass Transf 124:1245-1261

21. Zhou X, Braun JE (2004) Transient modeling of chilled water cooling coils. In: International refrigeration and air conditioning conference, paper 652

22. Fluent A, Ansys (2013) Release 15.0. Theory Guide, November

23. Versteeg HK, Malalasekera W (2007) An introduction to computational fluid dynamics: the finite method. Pearson Education, New York

24. Fatahian $\mathrm{H}$, Salarian $\mathrm{H}$, Nimvari ME, Fatahian E (2018) Numerical study of thermal characteristics of fuel oil-alumina and wateralumina nanofluids flow in a channel in the laminar flow. IIUM Eng J 19(1):251-269

25. Lima AAS, Ochoa AAV, Da Costa JAP, Henríquez JR (2019) CFD simulation of heat and mass transfer in an absorber that uses the pair ammonia/water as a working fluid. Int J Refrig 98:514-525

26. Qian Y, Han Z, Zhan JH, Liu X, Xu G (2018) Comparative evaluation of heat conduction and radiation models for CFD simulation of heat transfer in packed beds. Int J Heat Mass Transf 127:573-584

27. Fatahian E, Nichkoohi AL, Fatahian H (2019) Numerical study of the effect of suction at a compressible and high Reynolds number flow to control the flow separation over Naca 2415 airfoil. Prog Comput Fluid Dyn Int J 19(3):170-179
28. Yue C, Zhang Q, Zhai Z, Ling L (2018) CFD simulation on the heat transfer and flow characteristics of a microchannel separate heat pipe under different filling ratios. Appl Therm Eng 139:25-34

29. Fatahian H, Salarian H, Nimvari ME, Fatahian E (2018) Numerical study of suction and blowing approaches to control flow over a compressor cascade in turbulent flow regime. Int J Automot Mech Eng 15(2):5326-5346

30. Montazeri H, Blocken B, Hensen JLM (2015) Evaporative cooling by water spray systems: CFD simulation, experimental validation, and sensitivity analysis. Build Environ 83:129-141

31. Khalajzadeh V, Farmahini-Farahani M, Heidarinejad G (2012) A novel integrated system of ground heat exchanger and indirect evaporative cooler. Energy Build 49:604-610

32. Gebrehiwot B, Dhiman N, Rajagopalan K, Agonafer D, Kannan $\mathrm{N}$, Hoverson J, Kaler M (2013) CFD modeling of indirect/direct evaporative cooling unit for modular data center applications. In: ASME International technical conference and exhibition on packaging and integration of electronic and photonic microsystems. American Society of Mechanical Engineers

33. Martín RH (2009) Numerical simulation of a semi-indirect evaporative cooler. Energy Build 41(11):1205-1214

Publisher's Note Springer Nature remains neutral with regard to jurisdictional claims in published maps and institutional affiliations. 